This item was submitted to Loughborough's Research Repository by the author.

Items in Figshare are protected by copyright, with all rights reserved, unless otherwise indicated.

\title{
A comparison between stereolithography and aluminium injection moulding tooling
}

PLEASE CITE THE PUBLISHED VERSION

PUBLISHER

(c) Emerald Group Publishing Limited (MCB University Press)

LICENCE

CC BY-NC-ND 4.0

REPOSITORY RECORD

Hopkinson, Neil, and Phill M. Dickens. 2019. "A Comparison Between Stereolithography and Aluminium Injection Moulding Tooling”. figshare. https://hdl.handle.net/2134/3510. 
This item was submitted to Loughborough's Institutional Repository by the author and is made available under the following Creative Commons Licence conditions.

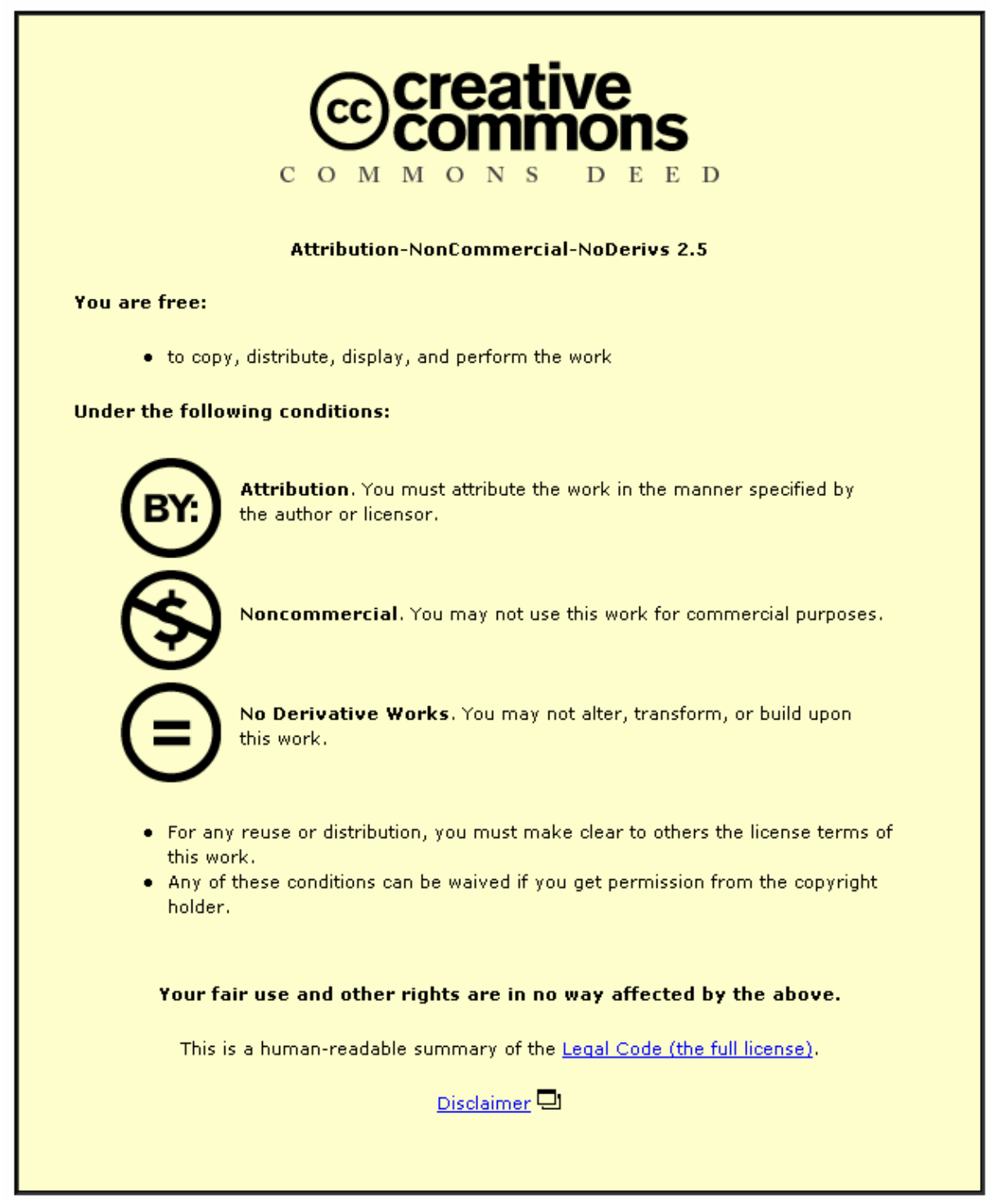

For the full text of this licence, please go to: http://creativecommons.org/licenses/by-nc-nd/2.5/ 
A Comparison Between Stereolithography and Aluminium Injection Moulding Tooling

Neil Hopkinson (nhopkins@dmu.ac.uk) is a Lecturer in the Rapid Manufacturing Research Group, Department of Mechanical and Manufacturing Engineering at De Montfort University, Leicester, UK. Tel +44 1162551551 x8064

Neil Hopkinson is a lecturer within the Rapid Manufacturing research Group at De Montfort University in Leicester; this position involves the management of technolgy transfer and research projects with a variety of industrial partners and the development of a new MSc in Rapid Product Development. With a PhD in Rapid Tooling, Neil's main areas of research are Rapid Tooling and Rapid Manufacturing.

Phill Dickens (pdickens@dmu.ac.uk) is the Professor of Manufacturing Technology in the Department of Mechanical and Manufacturing Engineering at De Montfort University, Leicester, UK. 


\section{$\underline{\text { ABSTRACT }}$}

Advances in rapid prototyping and machining have resulted in reduced lead times for injection moulding tooling. Comparisons between aluminium and stereolithography (SL) tools are made with regard to the ejection forces required to push mouldings from the tools, heat transfer through the tools and the surface roughness of the tools.

The results show that ejection forces for both types of tools are increased when a longer cooling time prior to ejection is used. The ejection forces required from a rough aluminium tool are considerably higher than those from a smooth aluminium tool.

SL tools do not appear to be subjected to any smoothing as a result of moulding polypropylene parts, this is explained by the fact that the tool's surface acts in a rubber like manner during part ejection. The rubber like nature of the tool's surface is as a direct consequence of the low glass transition temperature and low thermal conductivity of the tool material. Further potential benefits of the low thermal properties of the tool are discussed.

\section{$\underline{\text { KEYWORDS }}$}

Rapid prototyping, prototyping, rapid tooling, stereolithography, injection moulding. 


\section{$\underline{\text { BACKGROUND }}$}

The emergence of layer manufacturing technologies as a means of producing injection moulding tooling has offered significant benefits particularly with regard to the time required to create a tool. SL provides a good example where a layer manufacturing technique may be used to rapidly produce injection moulding tooling. However SL tools have limitations especially in terms of their low thermal and mechanical properties.

The low thermal conductivity of SL resin results in a long cycle time especially when the recommended procedure of using "cooling, cooling and more cooling” (Decelles, 1996) is adopted. The low glass transition temperature (Tg) of SL resins has also been cited as a reason why SL tools fail prematurely under injection pressures or, more commonly due to ejection forces (Jacobs, 1996) (see Figure 1). Previous research into the use of SL tools for injection moulding has assessed the effects on final moulding properties (Dawson 1998), the bending and shear strength of SL tools (Rahmati and Dickens 1997) and the efficacy of conformal cooling channels (Janckzky et al 1997), however no other investigations into the tensile tool failure as shown in Figure 1 have been published.

The research reported in this paper has focussed particularly on the tensile mode of SL tool failure during part ejection which is illustrated in Figure 1. Tensile failure during ejection occurs when the moulding freezes onto a core feature causing high friction between the core feature and the moulding. The tool will fail under tension during ejection if the friction between the core feature and the moulding is greater than the tensile strength of the core feature. 
As layer manufacturing techniques have evolved, traditional machining technology has improved with the development of high speed machining processes and easier machine tool programming. These developments have also had the effect of reducing lead times for tooling and justify the consideration of aluminium tooling when assessing rapidly produced injection moulding tools. Clearly aluminium injection moulding tools have higher thermal and mechanical properties than SL tools so a comparison of performance between similarly designed tools made from the different materials will help to identify the usefulness of SL tools in some context.

\section{Take in Figure 1}

\section{$\underline{\text { METHODOLOGY }}$}

When making an assessment of the usefulness of SL as an injection moulding material the first job is to identify the parameters of interest. Figure 1 illustrates the typical tensile mode of tool failure often encountered with SL injection moulding tools. This tensile failure is dependent on the ejection force required to push the moulding from the mould and the strength of the mould.

The ejection force is determined by a number of factors and an equation to predict it has been developed (Menges, 1986):

$$
\mathrm{F}_{\mathrm{e}}=\mu \mathrm{PA}
$$

Where $\mu \quad$ is the coefficient of friction between the mould and moulding. 
P is the contact pressure between the mould and the moulding.

A is the area of contact between the mould and the moulding parallel to the line of ejection

This equation indicates that important parameters, other than the tool material, which will affect the ejection force are the surface roughness of the mould as this will affect $\mu$ and the cooling time prior to ejection which will affect P. By using SL and aluminium versions of the same tool design, differences in the contact area between the mould and the moulding A may be neglected.

The tool strength is based on the cross sectional area of the core feature perpendicular to the line of ejection and the ultimate tensile strength of the tool material. SL resins have been shown to weaken dramatically at elevated temperatures (Hague, 1997) and so tool temperatures in the SL tool will prove critical to tool performance during ejection.

\section{Tools produced}

Three core inserts were produced for experimentation; one of these was an SL tool produced on an SLA250 machine using SL5170 resin. In order to maintain consistency with other SL tools used in other experiments this core was not subjected to any manual finishing other than wiping clean of excess resin prior to post curing. Two aluminium cores were used, one of these was machined to a smooth surface finish and the other was machined with a rougher surface finish in order to replicate as closely as possible the surface roughness on the SL tool. 
One SL and one aluminium cavity insert were produced to be used with a core of the same material for moulding. Figure 2 shows a picture of the cores and cavities used along with a complete moulding.

Take in Figure 2

\section{Injection Moulding cycles}

The tooling inserts shown in Figure 2 were housed in a die set which was fixed to a 60 ton Battenfeld injection moulding machine. Table I shows the parameters used to mould polypropylene parts using the different tooling materials. These parameters were based on previous injection moulding experiments using polypropylene in stereolithography tools (Rahmati, 1997). The cooling time prior to ejection was varied from shot to shot to assess its effect on the ejection force.

When moulding with the SL core the temperature at the centre of the core was allowed to cool to $55^{\circ} \mathrm{C}$, which is below the Tg, before the next shot was injected; this minimised the possibility of tool failure during injection.

\section{Take in Table I}

\section{$\underline{\text { Measuring Ejection Forces }}$}

The die set included three ejector pins and each of these had a load cell housed behind it as shown in Figure 3. This allowed the ejection forces developed through each of the three ejector pins to be measured and added together giving the total ejection force. The total ejection force was the tensile force which was applied to the core 
each time a part was ejected. The readings from the load cells were recorded using a data acquisition set up at a frequency of $1000 \mathrm{~Hz}$ for each load cell. The ejection force was recorded for each part which was ejected.

\section{Take in Figure 3}

\section{$\underline{\text { Surface Roughness Measurements }}$}

A surface profilometer was used to measure the surface roughness of the cores' surfaces prior to use. A total of 12 measurements were made from pre-determined positions on each core to ensure that the same points on each core were measured. Further measurements were taken from the cores' surfaces after a number of shots had been moulded and ejected in order to show any changes caused by moulding.

\section{Measuring Temperature Cycles}

In the SL core temperature readings were taken from two thermocouples which were located at the edge and centre of the core as shown in Figure 4. This allowed a rough idea of the temperature distribution across the cross section of the core to be inferred; it also gave an idea as to how quickly heat was transferred across the low thermal conductivity tool.

In the smooth aluminium core temperature readings were taken from a thermocouple located at the centre of the core as with thermocouple number 1 shown in Figure 4. This allowed a comparisson of the rate at which heat passed through the 
aluminium core to compared with that of the SL core. No thermocouple was used in the rough aluminium core as it was assumed that the heat transfer in both aluminium tools would be identical to each other. All temperature readings were recorded at 1 second intervals as this was found to be sufficient to accurately record changes in temperature.

Take in Figure 4

\section{$\underline{\text { RESULTS }}$}

Over 50 mouldings were produced using each of the three core inserts with no visible signs of damage to either the tools or the mouldings. This indicates that all the tools should be able to be used to produce considerably higher quantities of parts so long as the same processing parameters are used.

\section{Measured Ejection Force}

Figure 5 shows the ejection forces measured from the SL core using different cooling times prior to ejection. As expected longer cooling times resulted in higher ejection forces due to the increased contraction of the moulding onto the core. For any given cooling time prior to ejection there was some variation in the measured ejection forces of 50 to $180 \mathrm{~N}$ and the reason for this variation is unclear.

Take in Figure 5 
Figure 6 shows the ejection forces measured from both of the aluminium cores using different cooling times prior to ejection. The cooling times used with the aluminium cores were shorter than those used with the SL cores due to their higher thermal conductivity. As with the SL core, higher ejection forces were experienced with extended cooling times prior to ejection. One exception to this can be seen with the rough aluminium core where the mean ejection forced measured using the longest cooling time of 40s was lower than the mean recorded force when a 30s cooling period was used. The reasons for this decrease in ejection forces with an increased cooling time prior to ejection are unclear but could be attributed to the inherent variation in results noted in these experiments.

The most striking observation from Figure 6 is the effect of the surface roughness of the tool on the ejection force using aluminium tools. The ejection forces from the rough aluminium tool were generally between two and four times the values of those from the smooth aluminium core. It is also worth noting that the effect of increased cooling times does not appear to be as marked for the smooth core as for the rough core.

Take in Figure 6 


\section{$\underline{\text { Surface Roughness measurements }}$}

Table II shows the mean surface roughness measurements taken from each of the cores both prior to and after moulding. The mean Ra value for the SL core prior to moulding is consistent with previous measurements (Reeves, 1997) however the fact that there appeared to be no change after moulding was surprising. It had been expected that the SL core surface would be subjected to some smoothing particularly as mouldings were ejected.

The smooth aluminium tool was shown to have a 2 micron Ra prior to moulding which was far lower than that for the SL tool. There appeared to be no change in roughness as a result of moulding 50 parts on the smooth tool.

The rough aluminium tool had been machined to replicate the surface roughness of the SL tool as closely as possible. Unfortunately the closest possible roughness to be machined was almost two times that of the SL tool. The lower mean surface roughness after moulding suggests that the rough aluminium tool may have been subjected to some smoothing as a result of moulding, however the difference may be attributed to the inherent variations in measurements given that the repeatability of results from the profilometer could only be taken as +/- 1 to 2 microns.

Take in Table II 


\section{Measured Temperature Cycles}

Figure 7 shows the temperature cycles for a single moulding using the SL tool and a number of mouldings using the smooth aluminium tool. The fact that a number of moulding cycles for the aluminium tool were performed in the same time as a single moulding cycle with the SL tool highlights the differences in heat transfer between the tools.

Take in Table 7

The temperature cycle at the edge of the SL tool rose quickly to a peak of $98^{\circ} \mathrm{C} 15$ seconds after the start of melt injection. This sharp rise was as expected as the surface of the tool was in direct contact with the polypropylene which was injected at $185^{\circ} \mathrm{C}$. The temperature at the edge of the SL tool then fell slowly although it is significant to note that the temperature remained above the Tg for over 120 seconds.

The temperature cycle at the centre of the SL core actually fell by $2^{\circ} \mathrm{C}$ for the first 20 seconds after melt injection. The reason for this fall was due to the thermal lag of the material which was still cooling at the start of the moulding cycle. The low thermal conductivity of the SL resin meant that it took over 20 seconds before the effect of the hot polypropylene at the edge of the tool was transferred to the centre of the $16 \mathrm{~mm}$ diameter tool. The temperature then slowly rose to a peak value of $68^{\circ} \mathrm{C}$ 120 seconds after injection before slowly cooling until ready for the next shot. 
The temperature cycle at the centre of the aluminium tool was far shorter than that for the SL tool and rose to a peak of only $50^{\circ} \mathrm{C}$. A quicker cycle would probably result in higher starting and peak temperatures however this was not investigated.

\section{CONCLUSIONS}

All three core inserts were used to successfully injection mould over 50 parts in polypropylene. There appeared to be no damage to either the tools or the mouldings suggesting that, so long as the moulding parameters remained unchanged, catastrophic tensile failure should not occur. This means that the maximum batch size moulded would be limited by the length of the moulding cycle rather than by tensile tool failure.

\section{Processing Parameters}

In order to successfully injection mould parts with the SL core it was necessary to use different processing parameters than those required with the aluminium cores. In general lower processing parameters such as injection speed, temperature and pressure were required with the SL core to avoid tool failure during injection. It is worth noting that the low thermal conductivity of the SL tool facilitates injection using these lower parameters as the risk of shutting off is reduced. 


\section{Ejection forces}

As expected longer cooling times resulted in higher ejection forces for all the tools due to increased contraction and therefore greater contact pressure between the moulding and the core. This suggests that, in order to minimise the risk of tensile failure when ejecting parts from SL cores, as short a cooling time prior to ejection as possible should be adopted. The adoption of minimum cooling times prior to ejection is in contrast to the current recommended procedures for using these tools.

The results from the aluminium tools highlighted the dramatic effect of surface roughness on ejection forces. This suggests that by finishing SL tools to give a smooth surface reduced ejection forces may be achieved, this would also have the effect of minimising the risk of tensile core failure during part ejection.

\section{Surface Roughness}

The most surprising result from the surface roughness measurements was the fact that there appeared to be no change in the surface roughness of any of the tools as a result of moulding over 50 parts. This suggests that tool wear is not an issue when moulding small batches from polypropylene with these types of tools.

The fact that the SL tool showed no signs of wear was most surprising given the comparatively soft nature of the tool material. One possible reason why the SL tools showed no signs of wear is because the surface of the tool was above its $\mathrm{Tg}$ during ejection. This meant that the tool's surface was rubbery and compliant and therefore able to deform elastically as the moulding was pushed over it. This 
indicates that the low Tg and low thermal conductivity of the SL tool material actually work together to ease part ejection.

\section{$\underline{\text { Temperature Cycles }}$}

The effects of the different thermal conductivities of the two tool materials were evident in the temperature cycle measurements. The slower heat transfer and resultant long time cycles experienced with the SL tool suggest that, even if an SL tool may withstand the rigours of large runs, there will be a limit on feasible batch sizes due to the time taken to produce a single moulding. The exact limitations of such a batch size will depend on the times and costs required to produce alternative tools and is not within the remit of this research.

The low thermal conductivity of the SL tool also had the effect of delaying thermal weakening of the tool immediately after melt injection. This suggests that, particularly for larger cross sectioned features, a short cooling time prior to ejection will minimise the risk of tensile tool failure during ejection. Once again, this finding contradicts the current recommended procedures for a long wait prior to ejection.

\section{DISCUSSION}

The experimental results highlight a number of differences between aluminium and SL tools many of which may have been expected and some which had not been anticipated. Clearly, for some applications and with the correct processing conditions, 
SL tooling may be used produce parts as successfully (if not as quickly in terms of cycle times) as aluminium tools. Given the short lead times and relatively low cost of producing SL parts, especially with complex geometries, their use as injection moulding tools will prove beneficial in some cases. The long cycle times associated with SL tools limits their effectiveness for longer runs and the use of higher melting temperature moulding materials may prove prohibitive.

Contrary to conventional thought the low thermal conductivity of SL resin may be seen to offer some advantages including the delay of thermal weakening of the tool and allowing the tool's surface to remain above its Tg for an extended period to ease ejection. In addition the low thermal conductivity may allow the successful moulding into deep thin slots without cold shutting. This is particularly beneficial as long thin slots may be easily produced by SL but not by conventional milling. Furthermore the low thermal conductivity allows low pressure injection which may enable large parts to be produced using lower pressures on smaller injection moulding machines which would be difficult with metal tools. An example where this might prove beneficial is when producing short run prototype tooling for moulding on a small machine generally used for prototyping preventing unwanted downtime on a larger machine which is used predominantly for production. 


\section{$\underline{\text { REFERENCES }}$}

Dawson, K., 1998, The Effect of Rapid Tooling on Final Product Properties, Proceedings of North American Stereolithography Users Group Meeting, San Antonio, Texas, USA, March 3rd, 1998.

Decelles, P. and Barritt, M., “Direct AIM ${ }^{\mathrm{TM}}$ Prototype Tooling Procedural Guide”, 3D Systems, Valencia, California, USA, 1996, P/N 70275/11-12-96

Hague, R.J.M., “The Use of Stereolithography Models as Thermally Expendable Patterns in the Investment Casting Process”, Ph.D. Thesis submitted to the University of Nottingham, January 1999.

Jacobs, P.F., "Recent Advances in Rapid Tooling from Stereolithography”, Proceedings of the National Conference on Rapid Prototyping and Tooling Research, Buckinghamshire College, November 18-19, 1996, ISBN: 0852989822

Janczyk, R., McLaughlin,R. and McCarthy, S.P., 1997, Rapid Stereolithography Tooling for Injection Moulding: The Effect of Cooling Channel Geometry, Journal of Injection Moulding Technology, March 1997, Vol 1 No.1 pp 72 - 78

Menges, G., Morhen, P., “How to Make Injection Moulds”, Hanser Publishers, New York, 1986, ISBN 3-446-13666-5

Rahmati, S. and Dickens, P.M., 1997, Stereolithography Injection Mould Tooling, Proceedings of the $6^{\text {th }}$ European Conference on Rapid Prototyping and Manufacturing, 
Nottingham, UK, July 1 - 3 1997, ISBN 09519759 7 8, pp 213 - 224

Reeves, P.E., Dickens, P.M., Davey, N. and Cobb, R.C., “Surface Roughness of Stereolithography Models Using an Alternative Build Strategy”, Proceedings of the $6^{\text {th }}$ European Conference on Rapid Prototyping and Manufacturing, Nottingham, UK, July 1-3, 1997, ISBN 09519759 43, pp 85-94 


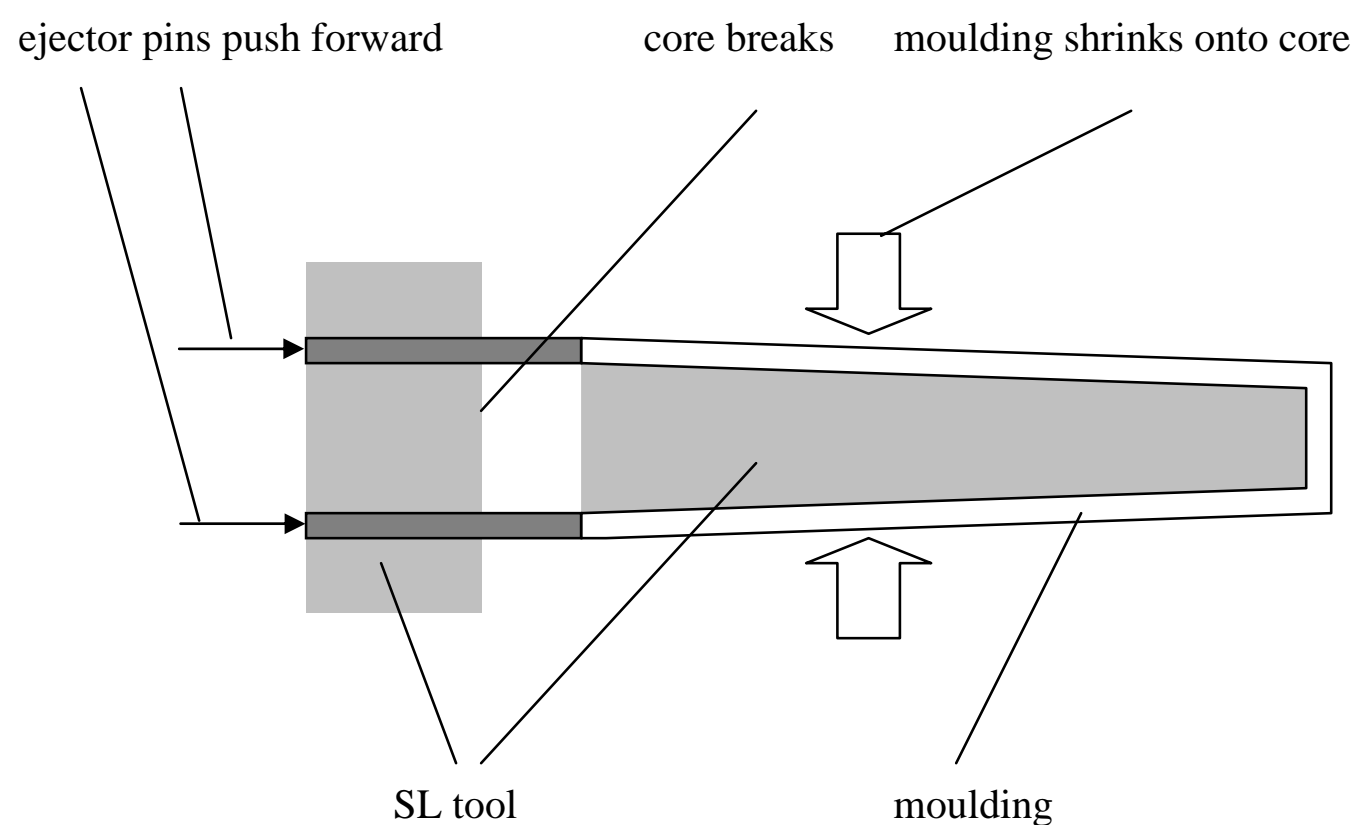

Figure 1. Moulding grips core feature which is pulled off during ejection.

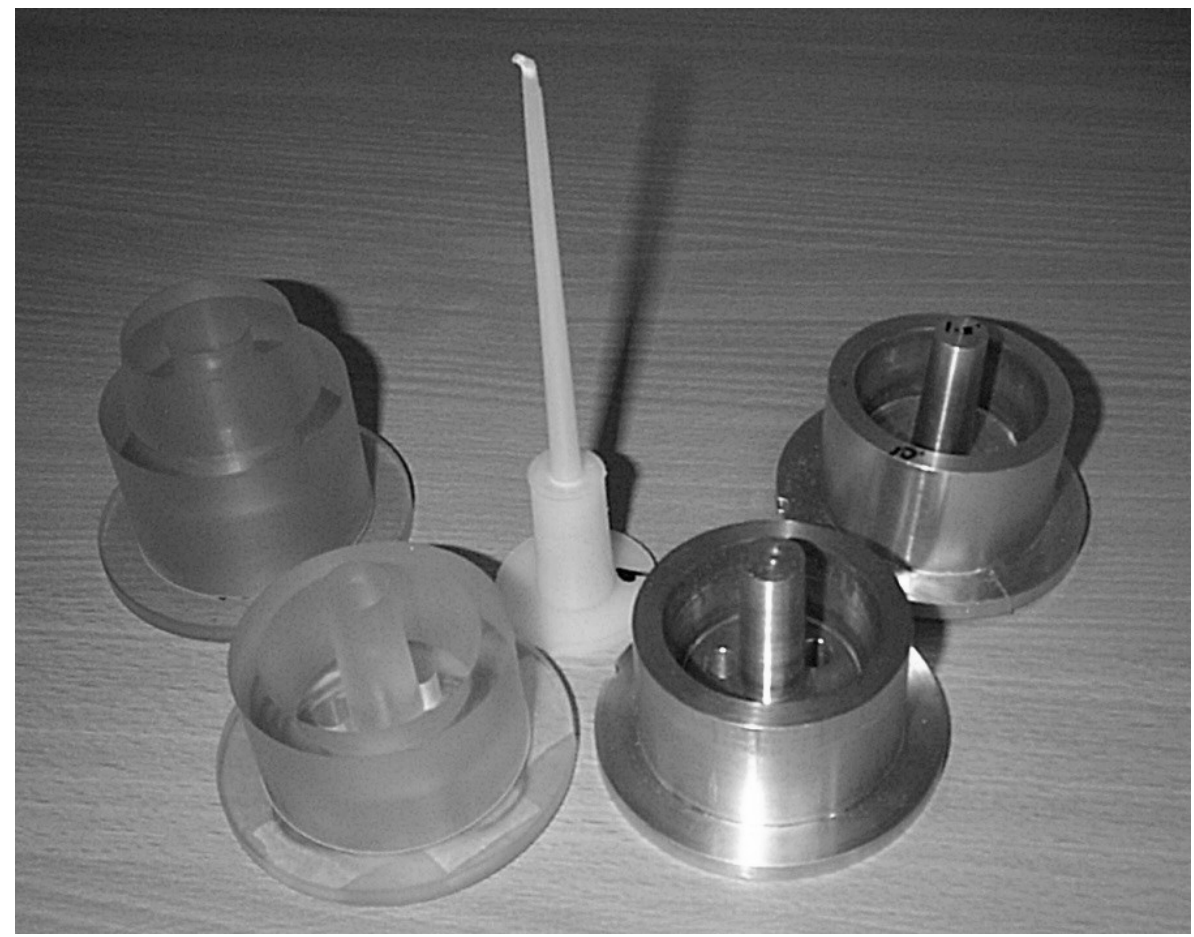

Figure 2. Cores and cavities used along with a complete moulding. 


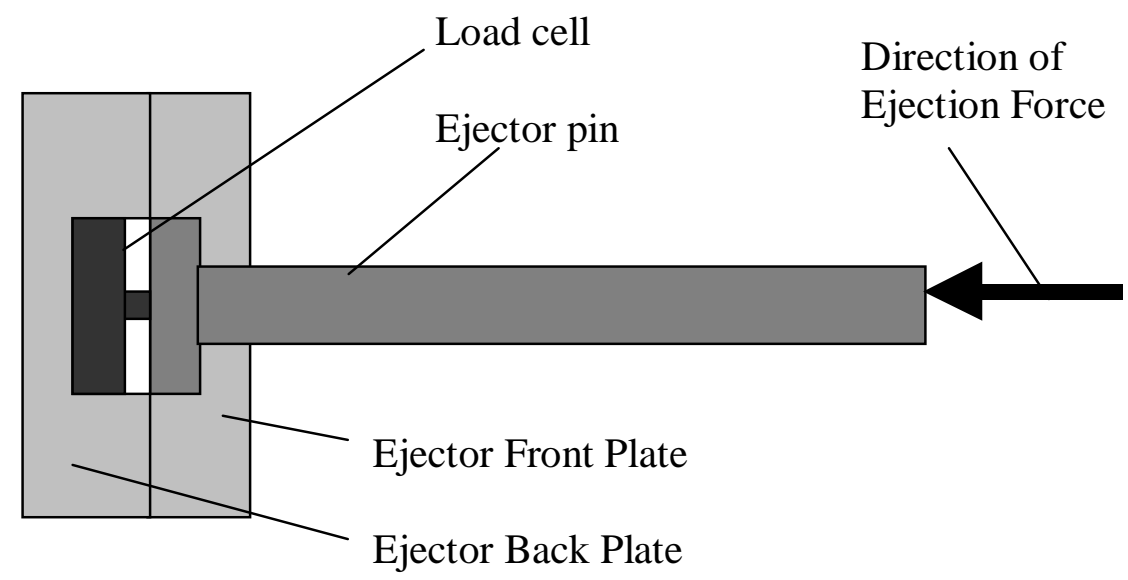

Figure 3. Load cell located behind ejector pin to measure ejection forces

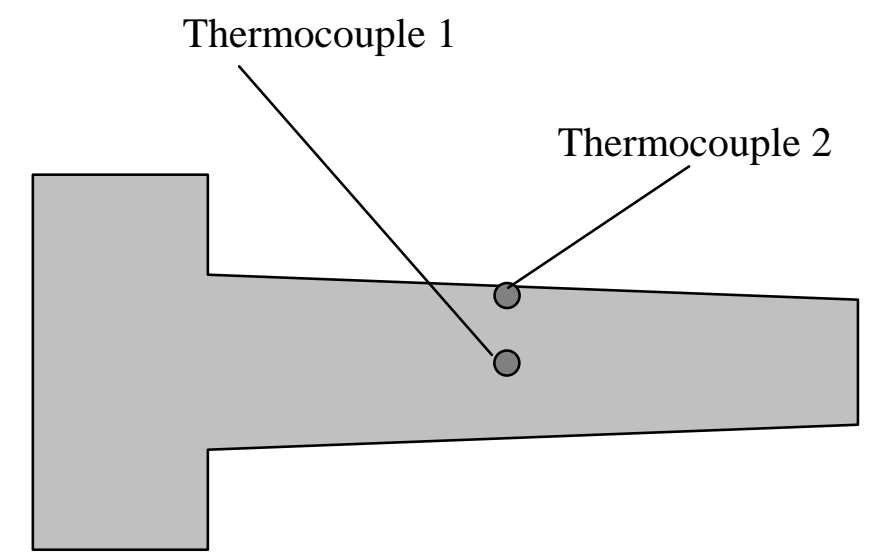

Figure 4. Location of the thermocouples within the core 


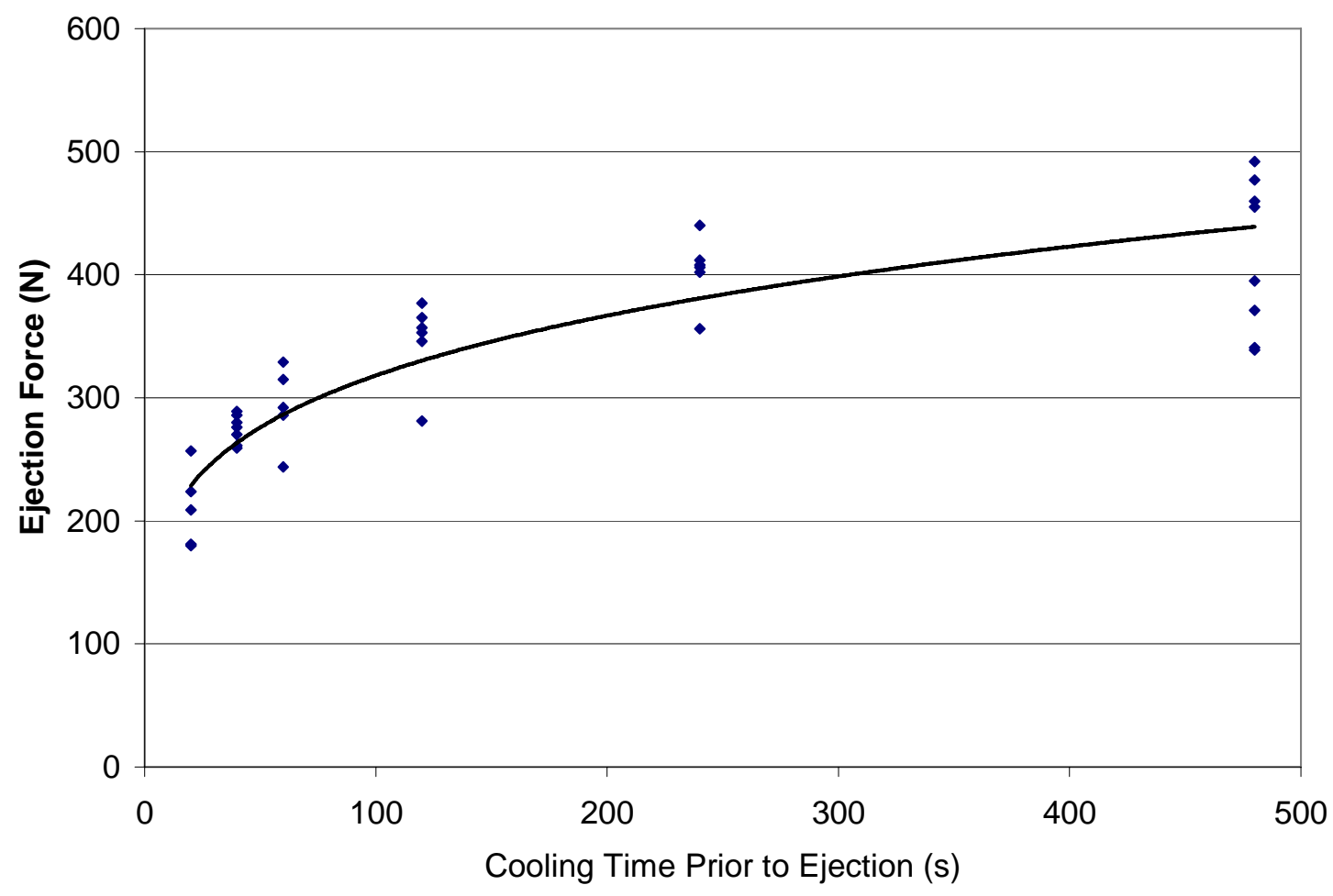

Figure 5. Graph showing effect of cooling time on ejection force with SL tool

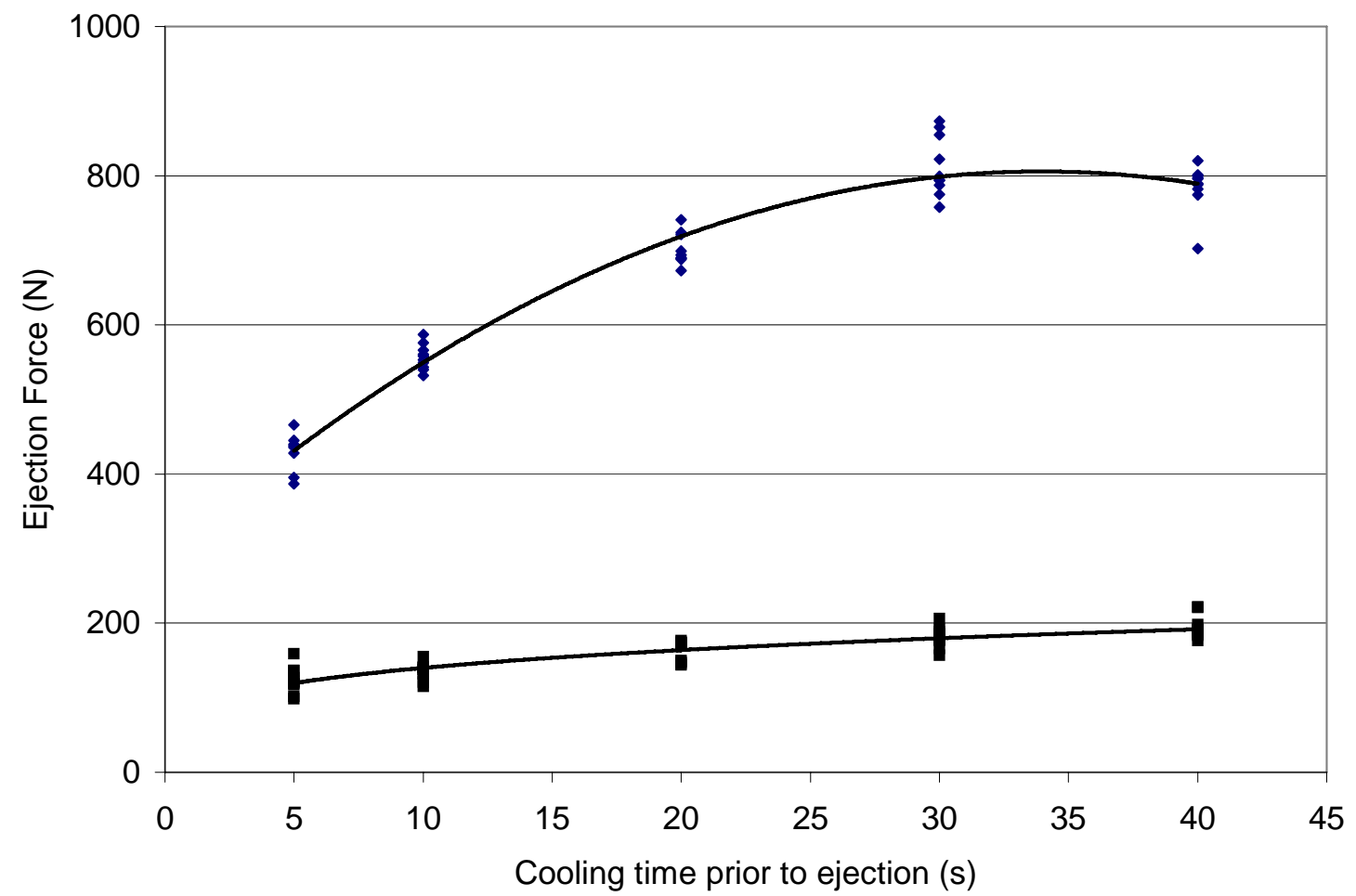

Figure 6. Graph showing effect of cooling time on ejection force with rough and smooth aluminium cores. 


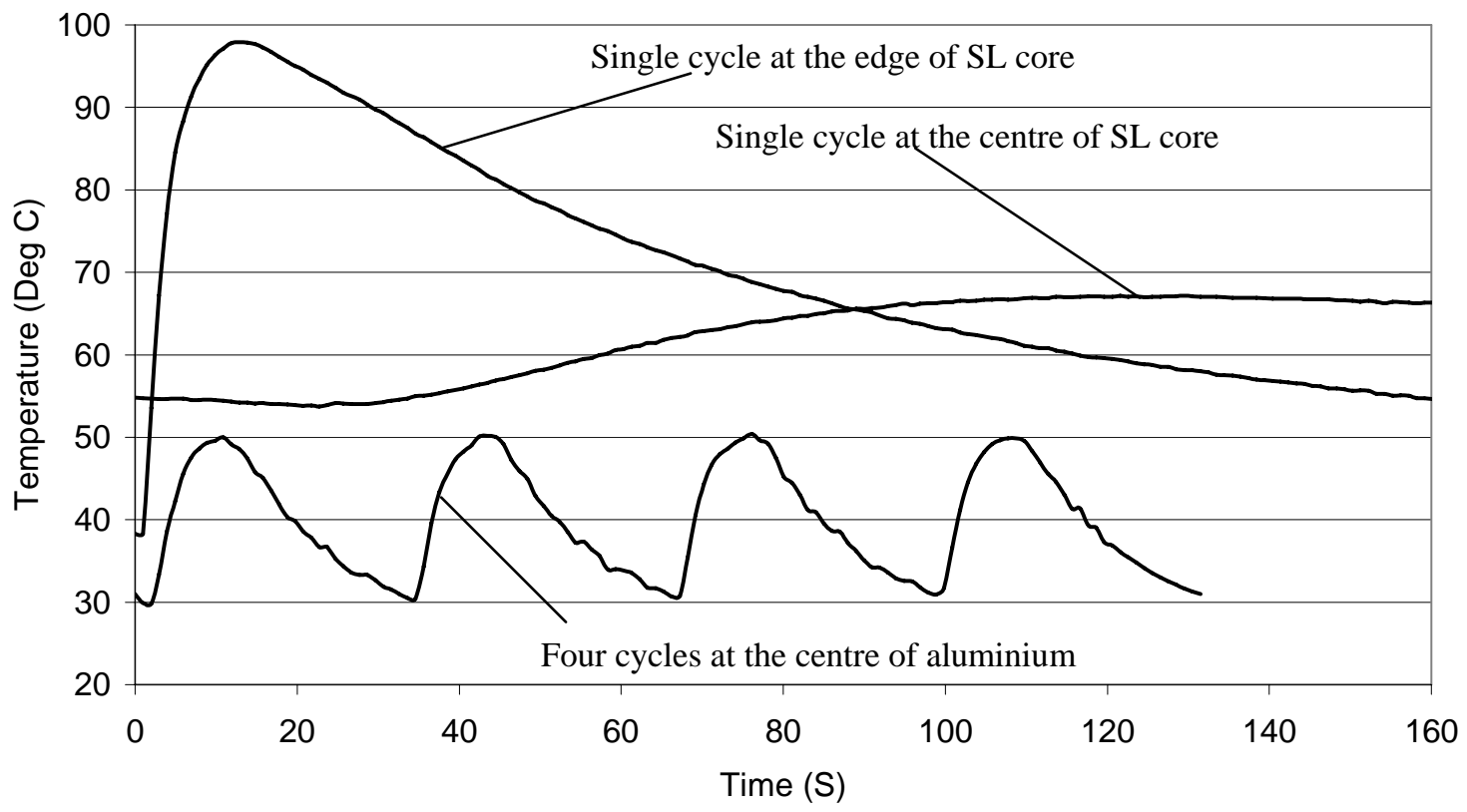

Figure 7. Graph showing temperature cycles from the start of melt injection in SL and aluminium tools 


\begin{tabular}{|c|c|c|}
\hline Moulding Process / Parameter & SL Tool & Aluminium Tool \\
\hline Mould Closing Pressure (MPa) & 5 & 40 \\
\hline Melt Temperature ( $\left.{ }^{0} \mathrm{C}\right)$ & 185 & 190 \\
\hline Injection Speed $\left(\mathrm{ms}^{-1}\right.$ ) & 0.08 & 0.32 \\
\hline Injection Pressure (MPa) & 10 & 40 \\
\hline Follow Up Pressure (MPa) & 0 & 0 \\
\hline Cooling Time (s) & $20-480$ & $5-45$ \\
\hline Ejection Speed (ms $\left.{ }^{-1}\right)$ & 0.8 & 0.8 \\
\hline mould open time (s) & 360 & 5 \\
\hline
\end{tabular}

Table I. Injection Moulding Process Parameters

\begin{tabular}{|c|c|c|}
\hline & $\begin{array}{c}\text { Mean Ra prior to } \\
\text { Moulding (um) }\end{array}$ & $\begin{array}{c}\text { Mean Ra After Moulding } \\
\text { (um) }\end{array}$ \\
\hline SL & 6 & 6 \\
Smooth aluminium & 2 & 10 \\
\hline
\end{tabular}

Table II. Surface roughness measurements both prior to and after moulding 
